\title{
Evaluation of the minimum age for consent to mental health treatment with the minimum age of criminal responsibility in children and adolescents: a global comparison
}

\author{
Mona Noroozi, ${ }^{1}$ llina Singh, ${ }^{2,3}$ Mina Fazel 2,4
}

${ }^{1}$ The Ohio State University, Columbus, Ohio, USA; ${ }^{2}$ Department of Psychiatry, University of Oxford, Oxford, UK; ${ }^{3}$ Wellcome Trust Centre for Ethics and the Humanities, Oxford, UK; ${ }^{4}$ Oxford Psychological Medicine Centre, The Children's Hospital, Oxford University Hospitals NHS Foundation Trust, Oxford, UK

Correspondence to Dr Mina Fazel, University Department of Psychiatry, Warneford Hospital, Oxford OX3 7JX, UK; mina.fazel@psych.ox.ac.uk

\section{ABSTRACT}

Background In many countries, a young person who seeks medical care is not authorised to consent to their own assessment and treatment, yet the same child can be tried for a criminal offence. The absence of child and adolescent mental health legislation in most countries exacerbates the issues young people face in independently accessing mental healthcare. Countries with existing legislation rarely define a minimum age for mental health consent (MAMHC). In stark contrast, nearly all 196 nations studied maintain legislation defining a minimum age of criminal responsibility (MACR).

Objective This review highlights inconsistent developmental and legal perspectives in defined markers of competency across medical and judicial systems.

Methods A review of the MAMHC was performed and compared with MACR for the 52 countries for which policy data could be identified through publicly available sources.

Findings Only $18 \%$ of countries maintain identifiable mental health policies specific to children's mental health needs. Of those reviewed, only 11 nations maintained a defined MAMHC, with 7 of 11 having a MAMHC 2 years higher than the country's legislated MACR.

Conclusions With increasing scientific understanding of the influences on child and adolescent decision making, some investment in the evidencebase and reconciliation of the very different approaches to child and adolescent consent is needed.

Clinical implications A more coherent approach to child and adolescent consent across disciplines could help improve the accessibility of services for young people and facilitate mental health professionals and services as well as criminal justice systems deliver optimal care.

\section{BACKGROUND}

An estimated $10 \%-15 \%$ of children and adolescents worldwide suffer from a functionally impairing mental illness, ${ }^{1}$ yet only a minority access services. ${ }^{2}$ There is increasing need to focus on the barriers to accessing mental healthcare for young populations as the evidence suggests that untreated mental illness has a significant detrimental impact on all aspects of development including learning, behaviour, social relationships and physical health. ${ }^{3}$ The negative impacts of mental health difficulties are felt not only in health and social outcomes but also in substance misuse and the criminal justice system, possibly as a result of increased risk-taking behaviour. ${ }^{4}$ In the USA alone, approximately $50 \%-75 \%$ of the 2 million youth encountering the juvenile justice system suffer from mental illness. ${ }^{5}$

One of the potential barriers to accessing mental health services is that children and adolescents need to have the additional consent of an identified adult to be accepted by most mental health services, unless they are deemed 'competent'. Mental health legislation across the globe is marked by poorly defined or otherwise absent guidance with few examples of comprehensive legislation, especially when including child and adolescent needs. ${ }^{6}$

However, many of the countries that insist for their children and adolescents to have parental consent for mental health treatment - usually up until the age of 18-often have criminal justice systems that maintain policies that qualify an adolescent's and occasionally even child maturity equivalent to that of adults, charging them with adult responsibilities and correspondingly harsh punitive judgements.

\section{Defining the age of consent: historical perspectives and neurobiological parameters}

The legal systems of many countries use an 'age of majority' strategy in determining consent rights. The age of majority is defined as the age at which an individual is considered an adult, that is, fully independent of parental or guardian oversight, actions and decisions. Age of majority is based on historical precedent rather than on developmental markers of psychological and physical maturity; for example, the physical capacity to serve as an artillery-carrying soldier in times of war has influenced many legal frameworks. ${ }^{7}$ During the First and Second World Wars, the age of majority was reduced from 21 to 18 in order to increase the number of available soldiers for combat. ${ }^{7}$ This change has persisted to the present day and consequently, in most countries, the age of majority is 18 years old. Thus, an arguably arbitrary determinant of adulthood has established the precedent for legal considerations of 'maturity', including the right to consent to medical procedures. ${ }^{89}$ Many nations require consent from primary caregivers and not from children (up until 18 years) for most medical procedures.

In contrast to historical precedent, neurobiology may provide a more objective means of establishing age of majority, but these insights alone do not necessarily provide clarity on the issue. Neurobiological parameters define the age of 'biological adulthood' as the age at which physical neurological adaptations have stabilised. Evidence of neurological changes that characterise maturation suggests that the processes are not as defined. For example, brain matter peaks as early as age $4,{ }^{10}$ yet there is ongoing development of the limbic system throughout adolescence, ${ }^{11} 12$ when synaptic density peaks in the medial prefrontal cortex. This area of the brain is involved in executive, attentional and regulatory functions. Substantial decline in synaptic density and overall neurological maturation does not occur until mid to late adolescence, typically completing around 24 years. ${ }^{10}$

In considering some of the cognitive and neurodevelopmental processes that contribute most to the issue of capacity to consent for both medical treatment and criminal responsibility, independent decision-making and the ability to reason are crucial. While these complex processes involve much of the brain, the maturation of the frontal lobe 


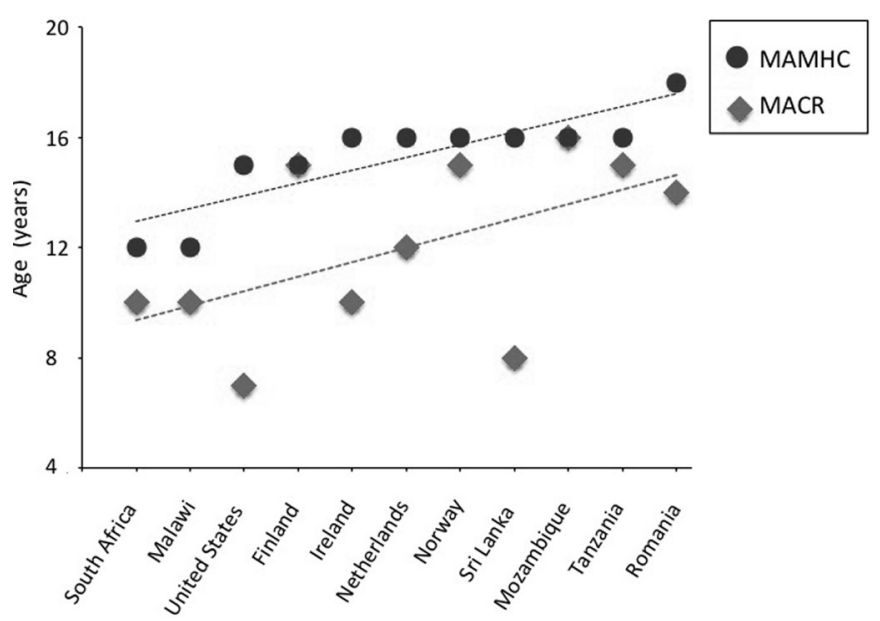

Figure 1 Differences between strictly defined MACR and MAMHC. Countries were chosen based on the presence of age determinants acquired by publicly available data. Dotted lines indicate trend differences in MACR compared with MAMHC across countries. In many countries, the definitive MAMHC is significantly higher than the MACR. MACR, minimum age of criminal responsibility; MAMHC, minimum age of mental health consent.

is key as it is involved in the regulation of emotions, impulse control, the ability to judge consequences as well as the implementation of executive function. Research suggests executive functions emerge during the first years of life and strengthen significantly with the continued development of the frontal lobe throughout adolescence and well into the early 20 s. $^{13-15}$

During adolescence, the frontal lobe experiences the greatest and most important structural change in the brain. In the early stage of brain development, the prefrontal cortex region of the frontal lobe undergoes a vast overproduction of grey matter. Prefrontal cortex grey matter reaches its maximal volume at 11.0 years in girls and 12.1 years in boys. Development of executive function, the set of mental skills that include working memory, inhibitory control and mental flexibility, results from this overproduction. In adolescence a second phase of brain development referred to as pruning of 'unused' grey matter occurs, strengthening neuronal synapses and organising the brain into its more 'mature' form. ${ }^{16}$ In regards to pruning of the prefrontal cortex, specific outcomes include an improvement in the ability to understand external perspectives in order to guide future behaviour. ${ }^{1417}$

\section{OBJECTIVE}

This paper examines legislation across the globe and compares the minimum age of mental health consent (MAMHC) to the minimum age of criminal responsibility (MACR). This comparison allows us to determine if there are discrepancies in the legal determination of competence, capacity and responsibility across health and justice sectors.

\section{METHODS}

Literature regarding MACR and MAMHC data was collected through PubMed and Google Scholar using the following search terms: international AND child AND adolesc* AND 'mental health AND policy' OR 'consent AND rights'. The MACR was defined as that which each nation had previously established ${ }^{18}$ as well as from public factsheets provided by YouthPolicy.gov. ${ }^{19}$

A review of the MAMHC was performed for the 52 countries for which policy data could be identified. Of those, only 11 nations maintained a defined MAMHC and were plotted against MACR (figure 1 and online supplementary Webappendix 1). Data for Brazil, Egypt,
Finland, India, Malaysia, Norway, Senegal, Sri Lanka and Tanzania were determined by Paxman and Zuckerman ${ }^{20}$ and the WHO Mental Health Atlas $2014 .^{21}$ Further MAMHC was determined by The Law Library of Congress $(U K)^{22}$ and in articles for Ireland ${ }^{23}$ and Iran. ${ }^{24}$ The MAMHC for Malawi, Ethiopia, Swaziland, Turkmenistan, Burkina Faso and Singapore was identified in a Human Rights textbook ${ }^{25}$ and that for South Africa in established legislation. ${ }^{26}$ Likewise, the MAMHC for Cyprus, the Czech Republic, Denmark, Estonia, Greece, Hungary, Lithuania, Portugal, Slovakia, Slovenia and Spain was determined from Stultiëns et al, 2007 27

MAMHC for each of the 50 US states was taken from the Guttmacher Institute, ${ }^{28}$ the National Defence Attorneys Association and state government websites. In states where no specific MAMHC is legislated, the federal age of majority (18) was used. In states where MAMHC is defined as 'mature minor,' the age of 12 was used based on traditional doctrine. In states that grant unrestricted minor consent access, the age of 7 was defined by the authors. To determine a uniform MAMHC for the USA, the modal MAMHC across all 50 states was selected.

For countries that did not have clearly established MAMHC guidelines, the MAMHC for these countries was recorded as 'not specified'. For countries with a MAMHC policy that allows mental health consent by mature minors or by patient request, the MAMHC for that country was determined by 'mature minor' or 'patient request', consistent with previously established standards. ${ }^{20}$

The international average age of majority was defined by the age of suffrage for each nation as provided by the USA Central Intelligence Agency. ${ }^{29}$ Child and adolescent mental health (CAMH) group designation was determined by standards set in Shatkin and Belfer $(2004)^{6}$ and confirmed by the WHO Mental Health Atlas 2014. ${ }^{21}$

\section{FINDINGS}

\section{Age of consent policies in medical and judicial contexts}

An ongoing survey of global mental health programmes and policies by the WHO has indicated that in 2002, approximately a quarter of countries across the globe, representing $30 \%$ of the world's population, lacked any mental health legislation. ${ }^{30} 31$ The mental health gap (mhGAP) - the discrepancy between mental health need and service availability — which is marked in low-income and middle-income countries, highlights how limited mental health services are in vast regions of the globe. ${ }^{30} 31$ Even when considering that 131 countries self-reported the presence of a stand-alone mental health policy, ${ }^{21}$ only 35 countries of 191 surveyed worldwide retained identifiable mental health policies that specifically concern adolescents and even fewer maintain specific legislative language defining MAMHC requirements. ${ }^{6} 32$

While most countries lack legislation defining MAMHC, nearly all the same countries had a clear MACR, with the global median MACR being 12 years. ${ }^{33}$ MACR is defined as the age at which a young person can be held criminally responsible and thus charged as an adult in court. MACR assumes that a child or adolescent (depending on that country's legislated age) possesses the adult-equivalent capacity to understand the intent, severity and potential consequences of a crime. MACR laws indicate the young person has the emotional, mental and intellectual ability to discern and be held responsible for their actions. ${ }^{34}$ Almost $90 \%$ of all countries maintain MACR laws that allow criminal prosecution of children and adolescents between age 0 and 14 years.

We performed a cross-national comparison of the MACR and CAMH Policies in countries where that information was publicly available and/ or definitively in existence. For each country, we evaluated the MACR in relation to the international average age of majority, recognised as 18 years. This analysis revealed considerable difference in definitions of maturity internationally as indicated by the wide variance in the MACR across nations. Additionally, the MACR for most countries tended to be considerably lower than the average legislated age of majority. 
200

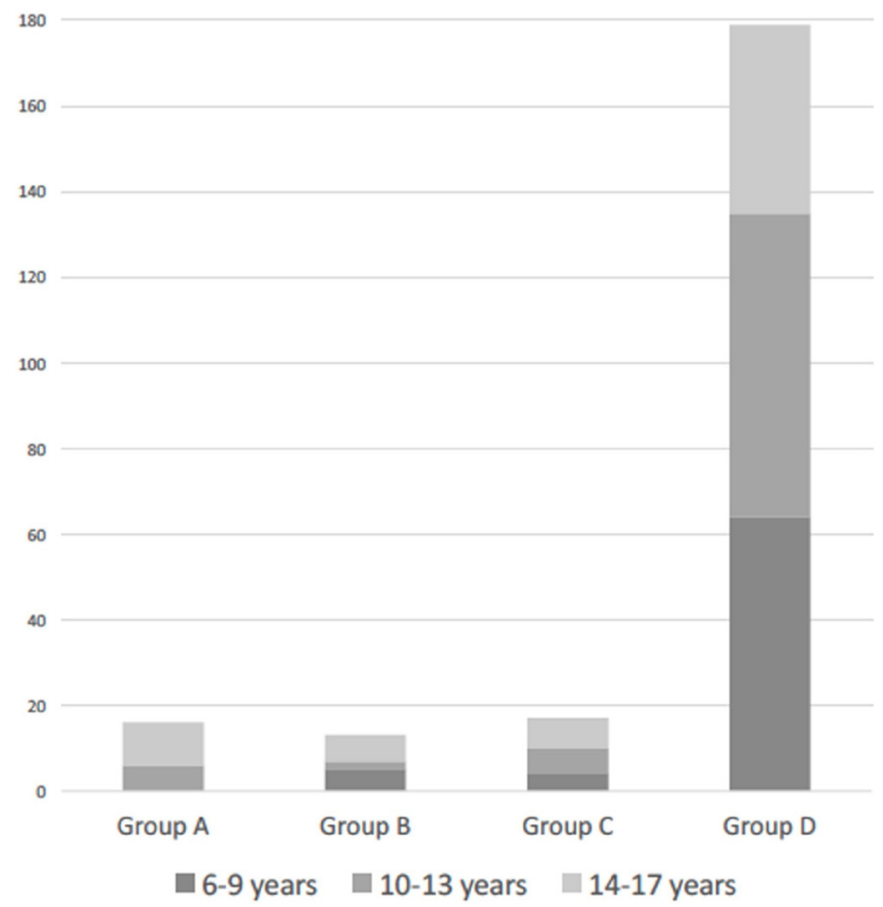

Figure 2 Global differences in national policy emphasis on children's mental health compared with that nation's minimum age of criminal responsibility (MACR). MACR is presented according to different age brackets (ages $0-9 ; 10-13 ; 14-17$ years) and compared with that country's policy status according to children's mental health needs. Those countries with more consideration for the specific needs of younger populations were categorised as Group A countries and depending on relevant factors other countries were grouped from $B$ to $D$ with those in Group $D$ having the least specific consideration of child and adolescent mental health needs in their national mental health policies.

We then compared the MACR with CAMH policies (figure 2 and online supplementary Webappendix 1). We conducted a number of analyses: first, we explored the difference in mental health policy type across countries with similar MACR ages across 52 countries. Of those surveyed countries, 14 countries with a median and modal MACR of 14 years were described as having a Group A mental health policy type, indicating the most sophisticated legislation that included a national policy or programme that both recognises the unique mental health needs of adolescents and clearly enumerates a national plan of action to address such needs. Group B mental health policies were those nations that recognise the developmental problems of adolescents but do not enumerate a unifying plan of action. These were present in 11 surveyed countries with a median MACR of 12 and modal MACR of 14 . Fourteen countries with a median MACR of 13 years made up Group C, defined as policies that recognise the mental health problems of adults with some beneficial impact on adolescent mental health needs. Countries not listed in Policy Groups A-C were assumed to fall under Group D, identified as countries with no clearly identifiable mental health policy. These 'Group D' countries have a median MACR of 13 years. Overall, these analyses suggest that only $7 \%$ of included countries have national policies that recognise and plan for the unique mental health needs of children and adolescents. ${ }^{62}$ This contrasts with a median MACR of 14 years (and a modal of 10 years), where children and adolescents are legally deemed responsible for their actions.

\section{Conflicting international policies on competency: MAMHC vs MACR}

The term mental competence is a legal judgement that maintains similar definitions across medicine and law. In law, competence refers to the aptitude to differentiate right from wrong as well as the ability to express oneself. ${ }^{35}$ Similarly, medical determination processes describe a patient's competence as the capacity to comprehend the presented information/diagnoses, weigh all options, make a decision and act independently. ${ }^{36}$ Capacity is a clinical assessment of a patient's physical, mental and emotional aptitude. In medicine, this is measured in terms of understanding the nature and consequences of a proposed treatment and treatment refusal. In law, the capacity to understand the nature and consequences of a committed crime and the ability to stand trial are assessed in determining a person's competency.

Nearly every nation maintains MACR legislation that declares an adolescent's competency to understand the implications of a crime and thus be tried as an adult. However, only a handful of nations have MAMHC legislation that support similar age/level of competency standards necessary for consent to mental healthcare. Consequently, in many countries, an adolescent who seeks medical help may not autonomously consent to evaluation without parental approval, but the same adolescent can be tried in court for a criminal offence.

Existing MAMHC and MACR legislations determine age of competency based on similar definitions of capacity. However, actual age of competency varies significantly between these legislations in a majority of countries. We directly compared the MAMHC to MACR specifically for counselling services, which is often considered a less intense and more available type of mental health intervention, across 52 countries where publicly accessible information related to such legislation existed. This analysis demonstrates that in most countries the definitive MAMHC is either poorly defined or is older than the MACR. When we restricted our analysis to the 11 countries with strictly defined MAMHC and MACR ages, more than $80 \%$ of these countries maintained different MAMHC and MACR ages, with 7 of the 11 countries having a MAMHC age between 2 and 8 years higher than the country's mandated MACR (figure 1).

The USA serves as an example of how large the gap between a nation's MAMHC can be from its mandated MACR. In the USA, 33 states have no set MACR, often applying a judicial capacity related test instead. Adolescents are thereby theoretically able to be sentenced to criminal penalties at any age..$^{37}{ }^{38}$ Of the 17 states that do set a MACR, North Carolina has the lowest at 7 years, while Wisconsin has the highest at 10 years. ${ }^{38}$ In comparison, 35 states require patients possess a MAMHC of at least 14-15 years or older. ${ }^{39}$ Of note, these are among the lowest global MAMHC.

Similar to US regulations, France maintains no absolute minimum age at which an adolescent can be held criminally responsible. Adolescents are considered to have 'discernment' between ages 8 and 10 and may be subjected to adult sentences by age $16 .{ }^{38}$ In contrast, France restricts an adolescent's ability to make independent medical decisions but does at times take age and maturity into consideration. ${ }^{40}$

Few cases of countries with similar MAMHC and MACR policies exist. Of those that do, the UK, Canada and Australia serve as better examples and are discussed below. The UK jurisdictions of England, Wales and Northern Ireland have legislation allowing adolescents under 16 to consent to medical care. For consent to be valid, the adolescent must pass a Gillick competency test demonstrating understanding of their condition and recommended treatment. ${ }^{22}$ Northern Ireland uses a 'sliding scale' in determining the importance of the adolescent's will with regard to a medical decision. ${ }^{23}$ In line with the UK's minimum age of medical consent laws, the UK maintains a MACR of 10 years. ${ }^{41}$ This suggests that adolescents possess the potential to be considered competent in the eyes of both a judge and a medical provider. Scotland's Age of Legal Capacity Act of 1991 upholds a competent adolescent's right to consent to medical treatment through a medical survey. The survey tests an 
adolescent's capacity to fully understand the nature of the treatment, the options, the risks involved and its benefits. ${ }^{42}$ Under these conditions, an adolescent and even an older child who has such understanding is considered Gillick competent. The parents cannot overrule the competent adolescent's consent. Scotland has a similarly fluid position on age of criminal responsibility: no child under 8 years may be guilty of any criminal offence. Thereafter, a child is considered capable of distinguishing between right and wrong, with possible prosecution starting from 12 years. $^{38}$

Minimum age of medical consent legislation in a number of Canadian territories has effectively made age irrelevant in determining an adolescent's capacity to request or refuse medical treatment. Instead, the concept of maturity has replaced chronological age. ${ }^{43}$ The Provinces of Quebec and New Brunswick have established a fixed age of medical consent that includes mental health evaluation at 14 and 16 years. ${ }^{44}$ Of note, Canada is also one of the few countries where health legislation matches Canada's MACR laws, under which a 12 year old is considered mentally capable of intentionally committing an offence and can be criminally convicted. ${ }^{38}$

In Australia, legislative provision and common law principles recognise and protect the developing competency of adolescents to make decisions regarding their own medical treatment. While parents and their adolescent children may hold concurrent rights to consent to the adolescent's treatment under specific circumstances, it is common for adolescents in Australia to provide independent consent to medical procedures when they are found to be of sufficient maturity. Maturity is defined as either a statutory age (14-16 depending on geographical jurisdiction), the ability to give informed consent to treatment ${ }^{45}$ or otherwise clinical assessment and confirmation by a practitioner of the adolescent passing a Gillick competency test. ${ }^{45}$ Historically, the MACR in common law was 7 years which has recently been updated to adopt a uniform MACR of 10 years. 3846

Low-income and middle-income countries have the highest proportions of adolescents in their populations and yet are the least likely to have any CAMH policies. ${ }^{32}$ In contrast, the Czech Republic, Denmark, Ireland, the Netherlands, New Zealand, Portugal, Chile and the UK, along with a few middle-income countries, including Ghana, Lithuania and South Africa, ${ }^{26}$ are identified as having the most substantially developed policies, possibly because they have a longer history of service development and availability of resources. ${ }^{632}$

\section{CONCLUSION}

This analysis demonstrates the non-uniformity of CAMH policies internationally, as only a few of the countries in Groups A-C had established consistent age markers for competency for both criminal responsibility and mental health consent. The maintenance of different legal thresholds for the age of medical and legal consent within a majority of countries is not aligned with the emerging evidence-base for the development of moral judgement, decision-making and responsibility. ${ }^{6} 32$ Responsibility for a crime requires an individual to have the capacity to make moral judgments, to understand social and legal norms and to weigh risks and consequences both for themselves and for others. ${ }^{47}$ Responsibility for medical decision-making requires the capacity to understand and to weigh information about the risks and benefits of a procedure and to engage in a reasoned decision-making process. While criminal responsibility entails another set of evaluative criteria, such as intent and motivation, the first order decision-making competencies in criminal acts and in medical decision-making are arguably sufficiently similar to warrant closer examination of the globally widespread differences in MACR and MAMHC legislation. We suggest this examination is particularly important in the context of mental health treatment, where the benefits of early intervention to treatment are significant and the barriers to accessing services are already high.
Currently the majority of countries have MAMHC laws incongruent with MACR laws, resulting in an adolescent not able to possess the same level of competency outlined in MACR laws to recognise and seek assistance for mental health issues. For example, while many high-income nations have replaced the arbitrary age of majority with a test of demonstrated capacity for children 6 years and older for the purposes of criminal prosecution, very few countries have legislated on adolescents' consent to mental health services. These nations justify that legislation on competency to consent to mental health treatment and competency to be prosecuted for a criminal offence use separate definitions of competency. Yet these legal inconsistencies are not based on cognitive or biological evidence that mental health decision-making and criminal responsibility engage different underlying neural mechanisms and, as suggested above, there may be good reasons for these laws to be better aligned. This would require better understanding of adolescent decision making and clarification of thresholds required for key cognitive competencies, such as judgement, reasoning and decision-making as tested in some competency tools including the MacArthur Competence Assessment Tool for Clinical Research (MacCAT-CR). ${ }^{48}$

\section{CLINICAL IMPLICATIONS}

In light of the increasing evidence supporting the importance of early access and treatment of mental illness, ${ }^{49} 50$ it is important to ensure that mental health legislation does not add a further hurdle for adolescents to access services. Moreover, inconsistencies between medical and legal thresholds for competency in adolescents have significant consequences for the management and care of vulnerable adolescents. Therefore, early identification of those whose cognitive and executive capacities are not developed sufficiently, and coordinated efforts to determine decision-making competencies, may well have a positive impact in the juvenile justice sector as well as in the mental health sector, as both criteria might benefit from re-evaluation in many countries across the globe.

The broader presence of developmentally sensitive legislation on the minimum age for mental health consent (MAMHC) would likely better facilitate competent young people to independently access and consent to mental health interventions. Below this age, consent of the parent/ guardian or the court is necessary for the purposes of a proposed treatment, unless the adolescent is deemed competent. We propose that these legislative limitations contribute to adolescents' inability to access needed and essential mental healthcare in a timely manner.

Establishment of MAMHC legislation rooted in scientific understanding can help implement consistency in the law. Development of standardised and objective tools/measures of adolescent competency could be a solution but will have implementation challenges, given the broad individual, diagnostic and procedural differences that they will be evaluating. If too stringent, then there is the danger that capable children might be wrongly excluded. At the very least, consistent approaches are recommended within a single country to match age of consent to mental healthcare with other measures of competency such as that used in the legal system.

Overall, these data suggest a need for more evidence on which to base legislation on medical and criminal decisions by better determination of when a young person can consent for mental health treatment. Following from this clarification, more uniformity in international CAMH policies are possible and better coherence between MAMHC and MACR.

Acknowledgements The authors thank Gabriela Pavarini and Anna Felnhofer for helpful comments on an earlier draft and Jess Shatkin for providing further clarification on data gathered.

Contributors MN acquired, analysed and interpreted the data. MF conceived of the paper and drafted the paper with MN. IS provided critical revision.

Funding MF was supported by the National Institute for Health Research (NIHR) Collaboration for Leadership in Applied Health Research and Care Oxford at Oxford 
Health NHS Foundation Trust. IS is funded by an Investigator award from the Wellcome Trust: 104825/Z/14/Z.

Disclaimer The views expressed are those of the author(s) and not necessarily those of the NHS, the NIHR or the Department of Health and Social Care. The funder had no role in the collection, analysis or interpretation of data, in the writing of the report or in the decision to submit the article for publication.

Competing interests None declared.

Patient consent Not required.

Provenance and peer review Not commissioned; externally peer reviewed.

(c) Author(s) (or their employer(s)) 2018. No commercial re-use. See rights and permissions. Published by BMJ.

- Additional material is published online only. To view please visit the journal online (http://dx.doi.org/10.1136/ebmental-2018-300032).

doi:10.1136/ebmental-2018-300032

Received 21 June 2018; Revised 29 June 2018; Accepted 2 July 2018

\section{REFERENCES}

1. Polanczyk GV, Salum GA, Sugaya LS, et al. Annual research review: A meta-analysis of the worldwide prevalence of mental disorders in children and adolescents. J Child Psychol Psychiatry 2015;56:345-65.

2. Olfson M, Druss BG, Marcus SC. Trends in mental health care among children and adolescents. N Engl J Med 2015;372:2029-38.

3. Patton GC, Sawyer SM, Santelli JS, et al. Our future: a Lancet commission on adolescent health and wellbeing. Lancet 2016;387:2423-78.

4. Fazel M, Hoagwood K, Stephan S, et al. Mental health interventions in schools in high-income countries. Lancet Psychiatry 2014;1:377-87.

5. Underwood L, Washington A. Mental Illness and Juvenile Offenders. Int J Environ Res Public Health 2016;13:228.

6. Shatkin JP, Belfer ML. The Global Absence of Child and Adolescent Mental Health Policy. Child Adolesc Ment Health 2004;9:104-8.

7. James TE. The Age of Majority. Am J Leg Hist 1960;4:22-33.

8. Gardner W, Scherer D, Tester M, et al. Cognitive development and adolescent legal rights. Am Psychologist 1989;44:895-902.

9. Johnson SB, Blum RW, Giedd JN. Adolescent maturity and the brain: the promise and pitfalls of neuroscience research in adolescent health policy. J Adolesc Health 2009;45:216-21.

10. Toga AW, Thompson PM, Sowell ER, et alTrends Neurosci 2006;29:148-59.

11. Sawyer SM, Afifi RA, Bearinger $\mathrm{LH}$, et al. Adolescence: a foundation for future health. Lancet 2012;379:1630-40.

12. Blakemore SJ, Robbins TW. Decision-making in the adolescent brain. Nat Neurosci 2012;15:1184-91

13. Xu F, Han Y, Sabbagh MA, et al. Developmental differences in the structure of executive function in middle childhood and adolescence. PLoS One 2013;8:e77770.

14. Best JR, Miller PH. A developmental perspective on executive function. Child Dev 2010;81:1641-60.

15. Alvarez JA, Emory E. Executive function and the frontal lobes: a meta-analytic review. Neuropsychol Rev 2006;16:17-42.

16. Lenroot RK, Giedd JN. Brain development in children and adolescents: insights from anatomical magnetic resonance imaging. Neurosci Biobehav Rev 2006;30:718-29.

17. Fuhrmann D, Knoll LJ, Blakemore SJ. Adolescence as a Sensitive Period of Brain Development. Trends Cogn Sci 2015;19:558-66.

18. Hazel N. Cross-national comparison of youth justice: Youth Justice Board, 2008 www.yjb.gov.uk. (accessed 13 Jun 2018).

19. Youth Policy. http://www.youthpolicy.org/factsheets/ (accessed 13 Jun 2018).

20. Paxman JM, Zuckerman RJ. Laws and Policies Affecting Adolescent Health. World Health Organisation, Geneva 1987.

21. World Health Organisation. World Mental Health Atlas 2014. Geneva, 2015. http:// www.who.int/iris/handle/10665/178879.
22. Law Library of Congress. Children's Rights: United Kingdom (England and Wales), 2015. July 02 ed.

23. Law Reform Commission. Children and the Law: Medical Treatment. 1393-3132. Ireland, 2011.

24. Parsapoor A, Parsapoor MB, Rezaei N, et al. Autonomy of children and adolescents in consent to treatment: ethical, jurisprudential and legal considerations. Iran J Pediatr 2014;24:241.

25. Parks A. Legal Minimum Age of Consent to Medical Treatment. Children and International Human Rights Law: The Right of the Child to be Heard 2013:82-7.

26. Ganya W, Kling S, Moodley K. Autonomy of the child in the South African context: is a 12 year old of sufficient maturity to consent to medical treatment? BMC Med Ethics 2016;17:66.

27. Stultiëns L, Goffin T, Borry P, et al. Minors and informed consent: a comparative approach. Eur J Health Law 2007;14:21-46.

28. Guttmacher Institute. www.guttmacher.org (accessed 13 Jun 2018).

29. Central Intelligence Agency. https://www.cia.gov/index.html laccessed 13 Jun 2018)

30. Funk M, Saraceno B, Pathare S, et al; Mental health legislation \& human rights. Geneva: World Health Organization, 2003.

31. Saraceno B, Saxena S. Mental health resources in the world: results from Project Atlas of the WHO. World Psychiatry 2002;1:40-4.

32. World Health Organization. Child and Adolescent Mental Health Resources AtlasGlobal Concerns: Implications for the future. Geneva: World Health Organization, World Psychiatric Association, International Association for Child and Adolescent Psychiatry and Allied Health Professionals. WHO Press, 2005.

33. Penal Reform International. The minimum age of criminal responsibility. 4: Justice for Children Briefing, 2013. http://www.penalreform.org/wp-content/uploads/2013/05/ justice-for-children-briefing-4-v6-web 0.pdf.

34. Penal Reform International. Protecting children's rights in criminal justice systems: A training manual and reference point for professionals and policymakers. London: Penal Reform International, 2013

35. Blacks Law Dictionary. Mental Competence. 2nd Ed: The Law Dictionary.

36. Thomas J, Moore G. Medical-legal Issues in the Agitated Patient: Cases and Caveats. West J Emerg Med 2013;14:559-65.

37. Cipriani D. Children's Rights and the Minimum Age of Criminal Responsibility: A Global Perspective: Ashgate, 2009.

38. Child Rights International Network. Minimum Ages of Criminal Responsibility Around the World: Child Rights International Network, 2016.

39. Kerwin ME, Kirby KC, Speziali D, et al. What Can Parents Do? A Review of State Laws Regarding Decision Making for Adolescent Drug Abuse and Mental Health Treatment. J Child Adolesc Subst Abuse 2015;24:166-76.

40. Bailly D. [lssues related to consent to healthcare decisions in children and adolescents]. Arch Pediatr 2010;17 Suppl 1(Suppl 1):S7-15.

41. Lyons B. Dying to be responsible: adolescence, autonomy and responsibility. Legal Studies 2010:30:257-78.

42. Great Britain. Age of Legal Capacity (Scotland) Act 1991. [Excerpt. 25 July 1991]. Current Law Statutes Annotated Great BritainSweet \& Maxwell, 1991:50.

43. Callaghan J, Young B, Pace F, et al. Evaluation of a New Mental Health Service for Looked after Children. Clin Child Psychol Psychiatry 2004; 9:130-48.

44. Medical Consent of Minors Act. 1976. SNB: c. M-6.1.

45. Library of Congress. Children's Rights: International and National Laws and Practice (Australia), 2007. http://www.loc.gov/law/help/child-rights/australia.php.

46. Urbas G. The Age of Criminal Responsibility. Australian Instit Criminology, 2000.

47. Herring $\mathbf{J}$. The age of criminal responsibility and the age of consent: Should they be any different. N Ir Legal 0 2016;67:343.

48. Hein IM, Troost PW, Lindeboom R, et al. Accuracy of the MacArthur competence assessment tool for clinical research (MacCAT-CR) for measuring children's competence to consent to clinical research. JAMA Pediatr 2014;168:1147-53.

49. Stallard $\mathbf{P}$. Children with mental health disorders have lower symptoms of depression 3 years after contact with mental health services. Evid Based Ment Health 2018;21:e2.

50. Miron JP, Abdel-Baki A. Cognitive-behavioural therapy can prevent transition to psychosis in ultra-high-risk participants in the long term. Evid Based Ment Health 2017;20:e10. 